\title{
ENRIQUEBELTRANIA, NOMBRE NUEVO PARA REEMPLAZAR A BELTRANIA MIRANDA (EUPHORPIACEAE)
}

\author{
J. Rzedowski*
}

En el No. 21 de este Boletín Faustino Miranda describió un género nuevo de euforbiáceas, basado en plantas colectadas en Yucatán (México), que llamó Beltrania. Este nombre, sin embargo, resulta ser homónimo de Beltrania 0 . Penzig, género de hongos con descripción publicada en 1882. Por tal motivo y de acuerdo con las reglas de nomenclatura botánica en vigor (Stafleu, F.A. et al., 1978, International Code of Botanical Nomenclature, Bohn, Scheltema \& Holkema, Utrecht, art. 64), la euforbiácea en cuestión requiere de una denominación nueva, misma que se propone a continuación.

Enriquebeltrania nom. nov.

Beltrania Miranda, Bol. Soc. Bot. Méx. 21: 11.1957 (tipo B. crenatifolta Miranda); non Beltrania O. Penzig, Nuovo Giorn. Bot. Ital. 14: 72 . 1882 (tipo: B. rhombica O. Penzig).

A su vez, la única especie conocida del género necesita de la siguiente transferencia:

Enruquebeltrania crenatifolia (Miranda) comb. nova.

Beltrania crenatifolia Miranda, Bol. Soc. Bot. Méx. 21: 12. 1957.

El nombre Enriquebeltrania honra al distinguido biólogo Dr. Enrique Beltrán, a quien originalmente fue dedicado también el género.

Agradezco al Dr. Gastón Guzmán, del Laboratorio de Micología, Escuela Nacional de Ciencias Biológicas, la ayuda prestada en la obtención de la literatura que facilitó el esclarecimiento de este problema.

\section{RESUMEN}

Se propone el nombre nuevo Enriquebeltrania para substituir a Beltrania Miranda (Euphorbiaceae), que resulta ser homónimo posterior de Beltrania O. Penzig, un género de hongos. Se designa asimismo la nueva combinación Enriquebeltrania crenatifolia (Miranda).

* Escuela Nacional de Ciencias Biológicas. Instituto Politécnico Nacional, México 17, D. F.; Becario de la C.O.F.A.A. del Instituto Politécnico Nacional.

Rzedowski J. 1979. Enriquebeltrania, nombre nuevo para reemplazar a Beltrania Miranda (Euphorbiaceae). Boletín de la Sociedad Botánica de México 38: 75-76. 
Enriquebeltrania nom. nov. is proposed as a substitute name for Beltrania Miranda (Euphorbiaceae), which is a later homonym of Beltrania O. Penzig, a genus of fungi. The new combination Enriquebeltrania crenatifolia (Miranda) is also proposed. 